\title{
REGIONAL ADVISORY BOARD POSITION STATEMENT ON OPTIMAL PNEUMOCOCCAL VACCINATION IN ADULTS UPDATE TO 2011 CONSENSUS ON ADULT PNEUMOCOCCAL DISEASE: UPDATE ON OPTIMAL PNEUMOCOCCAL VACCINATION IN ADULTS
}

\author{
Endre Ludwig ${ }^{1}$, Serhat Ünal' ${ }^{2}$ Miron Bogdan ${ }^{3}$, Roman Chlíbek ${ }^{4}$, Yavor Ivanov ${ }^{5}$, Roman Kozlov ${ }^{6}$, Hartmut Lode \\ Zsófia Mészner ${ }^{8}$, Roman Prymula ${ }^{9}$, Galia Rahav ${ }^{10}$, Anna Skoczyńska ${ }^{11}$, Ivan Solovič ${ }^{12}$, Abdullah Sayiner ${ }^{13}$ \\ ${ }_{1}^{1}$ Division of Infectious Diseases, Department of Internal Medicine No. II, Semmelweis Medical University, Budapest, Hungary \\ ${ }^{2}$ Section of Infectious Diseases, Department of Internal Medicine, Hacettepe University Faculty of Medicine, Ankara, Turkey \\ ${ }^{3}$ Carol Davila University of Medicine, Bucharest and Marius Nasta Institute of Pneumophthisiology, Bucharest, Romania \\ ${ }^{4}$ Department of Epidemiology, Faculty of Military Health Sciences, University of Defence, Hradec Králové, Czech Republic \\ ${ }_{5}^{5}$ Pulmonology and Phthisiatry Clinic, University Hospital, Pleven, Bulgaria \\ ${ }^{6}$ Institute of Antimicrobial Chemotherapy, Smolensk State Medical Academy, Smolensk, Russia \\ ${ }^{7}$ Research Center of Medical Studies (RCMS), Institute for Clinical Pharmacology, Charité University Medicine of Berlin, Berlin, Germany \\ ${ }^{8}$ National Institute of Child Health, Szent Laszlo Hospital for Infectious Diseases, Budapest, Hungary \\ ๑University Hospital, Hradec Králové, Czech Republic \\ ${ }^{10}$ Infectious Disease Unit, Sheba Medical Centre, Tel Hashomer, Ramat-Gan, Israel \\ ${ }^{11}$ National Reference Centre for Bacterial Meningitis, Department of Epidemiology and Clinical Microbiology, National Medicines Institute, \\ Warsaw, Poland \\ ${ }^{12}$ Pulmonology Department of National Institute for TB, Lung Diseases and Thoracic Surgery, Vyšné Hágy, Catholic University, Ružomberok, \\ Slovakia \\ ${ }^{13}$ Department of Chest Diseases, Ege University Medical Faculty, Izmir, Turkey
}

\section{SUMMARY}

Background: An important development in the field of adult pneumococcal vaccination since the last Consensus Statement, published by the Expert Panel of Central and Eastern Europe and Israel (the Region) in September 2012, was the licensure of the 13-valent pneumococcal conjugate vaccine (PCV13) for adults aged 50 years and older.

Discussion: The Expert Panel has developed this Position Statement as an update to its previous Consensus to address the following topics which are likely to be on the agenda of national scientific societies during the ongoing updates of vaccination recommendations in the Region: the availability of a pneumococcal conjugate vaccine for adults over 50 years of age, the available clinical evidence on its use in adults, and the future place of conjugate vaccines in adult pneumococcal vaccination. The Expert Panel concluded that there is sufficient epidemiologic immunogenicity and safety evidence to use PCV 13 in adults over 50 years of age.

Results: The use of conjugate vaccine induces immunological memory and can overcome some limitations associated with the plain polysaccharide vaccine (PPV). It was also agreed that, if the use of PPV is considered appropriate, PCV13 should be administered first, regardless of prior pneumococcal vaccination status.

Key words: invasive pneumococcal disease (IPD), community-acquired pneumonia (CAP), Central and Eastern Europe (CEE), Israel, pneumococcal vaccines, vaccination, elderly adults

Address for correspondence: Endre Ludwig, Division of Infectious Diseases,Department of Internal Medicine No. II, Semmelweis Medical University, 1097 Gyáli ut 5-7, Budapest, Hungary. E-mail: eludwig@laszlokorhaz.hu

\section{BACKGROUND}

Despite advances in prevention and medical management, S. pneumoniae infections continue to exert a significant burden on the adult population (1). Further, incidence and mortality of pneumococcal disease in adults start to rise at 50 years of age and reach a second peak among older adults that may exceed the significant disease burden recognized in children less than 5 years of age (2). Incidence of pneumococcal disease is currently underestimated, as bacteriological laboratory confirmation methods are underused and have limitations in their diagnostic yield. The definition of invasive pneumococcal disease (IPD) is ambiguous 
and varies in different sources since there is no consensus about whether laboratory methods beyond conventional bacteriological culture should be considered, e.g. PCR, BinaxNOW, etc. Further, limitations of the culture based bacteriology laboratory methods, together with the usually occurring previous antibiotic treatment, make it difficult to detect bacteremia in pneumonia cases and, therefore, to differentiate between bacteremic (invasive) and non-bacteremic (non-invasive) pneumococcal pneumonia. This is an important consideration since pneumococcal disease in adults presents most often as pneumonia.

Significant antibiotic resistance of $S$. pneumoniae in many countries of the Region suggests that there is a need for further optimization of prevention. In the majority of countries within the Region, pneumococcal vaccination in adults has been very limited due to low awareness among primary care professionals and the public, who tend to associate vaccination with children only. Additionally there is often a general, overriding negative connotation associated with vaccination. Data from randomized clinical trials and meta-analyses of studies evaluating the use of the plain polysaccharide vaccine (PPV) in adults have demonstrated a moderate decline of IPD incidence but little or no effect against pneumonia $(3,4)$. Repeat doses of PPV are generally not recommended for healthy adults by most of the guidelines, reflecting its limitations in providing protection through the long adult age period $(3,4)$, but may be suggested for specific circumstances in some countries (5). Pneumococcal conjugate vaccines (PCV) have led to significant reductions in disease burden in children, particularly where the vaccine has been incorporated into child vaccination programmes (CVP). Significant reductions in isolation of $S$. pneumoniae resistant to penicillin and macrolides were observed after the introduction of PCV7 vaccination in children $(6,7)$. A herd effect provided by PCV7, i.e. a reduction in the incidence of IPD caused by vaccine serotypes in unvaccinated age groups, has been observed in countries with national PCV7 CVP (8). However, there are PCV CVP countries which have not observed this, like the Czech Republic (9). The degree of herd effect on IPD and the speed at which it is achieved appears to be dependent in a large part on the vaccination strategy implemented, and coverage rate achieved in the CVP. Vaccine-mediated herd effects may reduce the probability of exposure to the pathogen (colonization) but do not provide personal immunity against disease.

\section{DISCUSSION}

\section{Use of Conjugate Pneumococcal Vaccination}

The use of conjugate technology in adult pneumococcal vaccination may overcome a number of limitations associated with the characteristics of polysaccharide vaccines $(10,11)$ including: short duration of effectiveness (12), little or no efficacy on community acquired pneumonia (13), no effect on nasopharyngeal carriage, and depletion of serotype specific memory and B1bcell subsets (12). Generally, conjugate vaccines provide higher functional antibody levels than polysaccharide vaccines (14) by creating an immune memory and do not blunt immunologic response to secondary vaccination (hyporesponsiveness). Conjugate vaccines can also reduce serotype-specific nasopharyngeal carriage (15). Conjugate vaccines, such as the ones against Haemophilus influenzae Type B (Hib), meningogoccal Group $\mathrm{C}$ (MenC), and pneumococci, have proven to be effective in children $<2$ years of age, an age group in which polysaccharide vaccines are known to be non-immunogenic and have no impact. Additionally, in HIV-positive adults, clinical trials with PCV7 have shown significant efficacy in protecting against vaccine serotype-specific IPD (16).

\section{Immunogenicity and Safety of PCV13 in Adults}

There is a substantial body of evidence demonstrating immunogenicity and safety of PCV13 in adults who have or have not previously received a dose of pneumococcal polysaccharide vaccine (PPV) (17).

PCV13 provides comparable levels of immunogenicity for all common serotypes (superior immunogenicity for the majority of common serotypes) to those provided by PPV, in both naive and previously PPV-vaccinated adults (17). There is also a demonstration of immunological memory 3-4 years following a primary vaccination with PCV13, whereas PPV was clearly shown not to induce immunological memory (18). Depending on clinical circumstances, PCV13 may also be administered concomitantly with seasonal trivalent inactivated influenza vaccine $(17,19,20)$, where this can facilitate vaccination of older adults who might fail to return for a subsequent vaccination $(17,19,21)$.

\section{Approvals and Recommendations of PCV13 for Adults}

As of March 2012, PCV13 was licensed for use in adults aged 50 years and older by the European Medicines Agency (EMA) and Food \& Drug Administration (FDA) in the USA. Based on the available approvals depending on the existing evidence, PCV13 may be used for adults over 50 years of age and can be administered in both naive and PPV-vaccinated adults. If PPV use is considered appropriate, it is recommended that PCV13 should be administered first to enable revaccination with either PCV13 or PPV at a later stage. As mentioned by the latest EMA Committee on Medicinal Products for Human Use (CHMP) assessment report, PCV13 can induce immune memory, which is a favourable and encouraging vaccine characteristic for revaccination. Vaccination decisions would also take into account individuals with conditions which place them at high risk of pneumococcal disease. Vaccination with PCV13 in specific immunocompromised groups should be considered on an individual basis.

After the EMA and FDA approval decisions, the availability of PCV13 for adults has already been addressed in several 2012 updates of national pneumococcal vaccination schedules. A number of European countries including Austria, Greece and five countries of the Region (Bulgaria, Estonia, Hungary, Lithuania, and Poland) have recommended the use of PCV13 for all adults over 50 years of age (22-28). In the Czech Republic, France (29), the Netherlands (30), Spain (31), Switzerland (32), and the USA (5), PCV13 has been recommended for use in adults of certain high-risk groups. The UK (33) and German (34) schedules have remained as they were with PPV use in adults over 65 and 60 years of age, respectively. 


\section{Implementation of Vaccination Guidelines}

Public awareness campaigns and education of healthcare professionals have to be considered to improve the impact of evidence-based guidelines on real-life healthcare. Guidelines for vaccination are developed by academic societies based on scientific evidence, while their implementation is affected by the level of education, awareness and preconceptions of primary care physicians, public, and policy makers as well as economic factors. Awareness and education programmes for all healthcare and lay audiences should be conducted, not only specifically around adult pneumococcal disease, but also in the broader context of "Healthy Ageing" and the importance of adult vaccination. Currently available data from countries with strong epidemiology networks, which have long shown the significant burden of pneumococcal disease and the causative serotypes across all ages $(2,35)$ should be communicated to primary care physicians, public and policy makers. Scientific evidence on vaccination against pneumococcal diseases should be communicated in the Region to reenforce the existing general agreement that all at-risk groups should be vaccinated. Practicing physicians will need clear educational and reference materials to make practical choices surrounding vaccination regimens for adult patients.

\section{Future Research}

Epidemiologic, microbiologic, clinical, and health economic research is important in the fields of pneumococcal disease in general and specifically in adult pneumococcal vaccination. Development of affordable diagnostic methods with improved sensitivity and specificity for pneumococcal disease would allow for more accurate ascertainment of the true disease burden. International studies with unified robust methodology and centralized data centers are needed to generate comparable data on antibiotic resistance. Health economic models and studies (including those assessing the costs of non-vaccination), can also support decisions on the national funding of age-based pneumococcal vaccination in adults 50 years of age and older. Post-licensure studies in adults will further explore the influence of PCV13 programmes on the distribution and morbidity of S. pneumoniae serotypes; they will ultimately demonstrate the impact of PCV13 on adult pneumococcal disease, including IPD and pneumonia, extending the evidence already available on the impact of PCV7 and PCV13 vaccination programmes in children.

\section{CONCLUSIONS}

Addressing the preventable burden of disease in older adults is essential in the context of healthy ageing, which is increasingly important in the countries of the Region. Further to the Call to Action published in its recent Consensus paper (1), the Expert Panel agreed, that the international licensure of a conjugate vaccine PCV13 for adults over 50 years of age represent a significant development in the field of adult pneumococcal vaccination. These approvals acknowledge the substantial body of evidence on safety and immunogenicity of PCV13 in adults. The use of the conjugate vaccine can provide additional opportunities for adults, such as the proven immunological memory which may help in lessening the significant burden of adult pneumococcal disease in the Region. The Expert Panel also emphasizes the importance of evidence-based vaccination recommendations and guidelines and effective educational activities for the relevant health care personnel.

\section{Conflict of Interests}

Endre Ludwig: Financial support for participating and working as consultant in advisory boards by Astellas, MSD; Honoraria as speakers in scientific meetings by Bayer.

Roman Chlíbek: Principal investigator in clinical studies supported by GlaxoSmithKline and Novartis; Scientific consultant to Baxter, GlaxoSmithKline, Novartis, Aventis Pasteur and Pfizer; Sponsorship from GlaxoSmithKline and Aventis Pasteur to attend scientific meetings.

Yavor Ivanov: Principal investigator in clinical trials sponsored by GlaxoSmithKline, Novartis, AstraZeneca. Lecture fees from GlaxoSmithKline, Novartis, AstraZeneca, Boerhinger Ingelheim.

Zsofia Meszner: Financial support for participating and working as consultant in advisory boards by Pfizer, GlaxoSmithKline and Sanofi. Roman Prymula: Received honoraria and research grants form GlaxoSmithKline, Pfizer, and Sanofi-Pasteur.

Anna Skoczyńska: Assistance to attend scientific meetings; honoraria for lecturing funded from Pfizer and GlaxoSmithKline.

Abdullah Sayiner: Received honoraria for lectures from GlaxoSmithKline and Pfizer.

Serhat Unal: Financial support for participating and working as consultant in advisory boards by, MSD; Pfizer, Honoraria as speakers in scientific meetings by Bayer, Pfizer.

\section{Acknowledgements}

Editorial assistance for the manuscript was provided by Dr. Dmitry Nonikov, Edelman, London, and funded by Pfizer Inc.

Financial support for the Regional Advisory Board on Pneumococcal Diseases in Adults was provided by Pfizer, Inc.

\section{REFERENCES}

1. Ludwig E, Ünal S, Bogdan M, Chlibek R, Ivanov Y, Kozlov R, et al. Opportunity for healthy ageing: lessening the burden of adult pneumococcal disease in Central and Eastern Europe, and Israel. Cent Eur J Public Health. 2012 Jun;20(2):121-5.

2. Motlová J, Kozáková J, Kř́žová P. Invasive pneumococcal disease in the Czech Republic in 2010. Zpr Epid Mikrobiol. 2011;20(2):64-9. (In Czech.)

3. 23-valent pneumococcal polysaccharide vaccine. WHO position paper. Wkly Epidemiol Rec. 2008 Oct 17;83(42):373-84.

4. European Centre for Disease Prevention and Control (ECDC). Technical Report of the Scientific Panel on Vaccines and Immunisation. Use of pneumococcal polysaccharide vaccine for subjects over 65 years of age during an inter-pandemic period [Internet]. Stockholm: ECDC; 2007 [cited 2013 Nov 21]. Available from: http://ecdc.europa.eu/en/ publications/Publications/0701_TER_Use_of_pneumococcal_polysaccharide vaccine.pdf

5. Centers for Disease Control and Prevention (CDC). Use of 13-valent pneumococcal conjugate vaccine and 23-valent pneumococcal polysaccharide vaccine for adults with immunocompromising conditions: recommendations of the Advisory Committee on Immunization Practices (ACIP). MMWR Morb Mortal Wkly Rep. 2012 Oct 12;61(40):816-9.

6. Imöhl M, Reinert RR, Mutscher C, van der Linden M. Macrolide susceptibility and serotype specific macrolide resistance of invasive isolates of Streptococcus pneumoniae in Germany from 1992 to 2008. BMC Microbiol. 2010 Nov 25;10:299.

7. Fenoll A, Aguilar L, Giménez MJ, Vicioso MD, Robledo O, Granizo $\mathrm{JJ}$, et al. Variations in serotypes and susceptibility of adult non-invasive Streptococcus pneumoniae isolates between the periods before (May 
2000-May 2001) and 10 years after (May 2010-May 2011) introduction of conjugate vaccines for child immunisation in Spain. Int J Antimicrob Agents. 2012 Jul;40(1):18-23.

8. Fitzwater SP, Chandran A, Santosham M, Johnson HL. The worldwide impact of the seven-valent pneumococcal conjugate vaccine. Pediatr Infect Dis J. 2012 May;31(5):501-8.

9. Motlová J, Beneš Č, Kozáková J, Kř́ižová P. Invasive pneumococcal disease in the Czech Republic in 2011. Zpr Epid Mikrobiol. 2012;21(2):51-8. (In Czech.)

10. Chilosi M, Poletti V, Rossi A. The pathogenesis of COPD and IPF: distinct horns of the same devil? Respir Res. 2012 Jan 11;13:3.

11. Moberley SA, Holden J, Tatham DP, Andrews RM. Vaccines for preventing pneumococcal infection in adults. Cochrane Database Syst Rev. 2008 Jan 23;(1):CD000422.

12. Clutterbuck EA, Lazarus R, Yu LM, Bowman J, Bateman EA, Diggle L, et al. Pneumococcal conjugate and plain polysaccharide vaccines have divergent effects on antigen-specific B cells. J Infect Dis. 2012 May 1;205(9):1408-16.

13. Huss A, Scott P, Stuck AE, Trotter C, Egger M. Efficacy of pneumococcal vaccination in adults: a meta-analysis. CMAJ. 2009 Jan 6;180(1):48-58.

14. de Roux A, Schmöle-Thoma B, Siber GR, Hackell JG, Kuhnke A, Ahlers $\mathrm{N}$, et al. Comparison of pneumococcal conjugate polysaccharide and free polysaccharide vaccines in elderly adults: conjugate vaccine elicits improved antibacterial immune responses and immunological memory. Clin Infect Dis. 2008 Apr 1;46(7):1015-23.

15. Hammitt LL, Bruden DL, Butler JC, Baggett HC, Hurlburt DA, Reasonover A, et al. Indirect effect of conjugate vaccine on adult carriage of Streptococcus pneumoniae: an explanation of trends in invasive pneumococcal disease. J Infect Dis. 2006 Jun 1;193(11):1487-94.

16. French N, Gordon SB, Mwalukomo T, White SA, Mwafulirwa G, Longwe $\mathrm{H}$, et al. A trial of a 7-valent pneumococcal conjugate vaccine in HIVinfected adults. N Engl J Med. 2010 Mar 4:362(9):812-22.

17. Summary of product characteristics. Prevenar13 [Internet]. London: European Medicines Agency; 2012 [cited 2013 Nov 21]. Available from: http://www.ema.europa.eu/docs/en_GB/document_library/EPAR_Product Information/human/001104/WC500057247.pdf.

18. European Medicines Agency. Prevenar 13: pneumococcal polysacharide conjugate vaccine (13-valent, adsorbed) [Internet]. European Medicines Agency; 2011 [cited 2013 Nov 21]. Available from: http://www.ema. europa.eu/docs/en GB/document library/Summary of opinion/human/001104/WC500112838.pdf.

19. Schwarz TF, Flamaing J, Rümke HC, Penzes J, Juergens C, Wenz A, et al. A randomized, double-blind trial to evaluate immunogenicity and safety of 13-valent pneumococcal conjugate vaccine given concomitantly with trivalent influenza vaccine in adults aged $\geq 65$ years. Vaccine. $2011 \mathrm{Ju}$ 18;29(32):5195-202.

20. Frenck RW Jr, Gurtman A, Rubino J, Smith W, van Cleeff M, Jayawardene $\mathrm{D}$, et al. Randomized, controlled trial of a 13-valent pneumococcal conjugate vaccine administered concomitantly with an influenza vaccine in healthy adults. Clin Vaccine Immunol. 2012 Aug;19(8):1296-303.

21. Schwarz TF, Schmoele-Thoma B. Assessment of functional antibacterial opsonophagocytic antibodies elicited by 13-valent pneumococcal conjugate vaccine administered concomitantly with trivalent influenza vaccine in a randomized clinical trial in adults aged $\geq 65$ years. Vaccine. 2013 Jan 2;31(2):291-4

22. Federal Ministry of Health. Austrian vaccination plan 2013 [Internet]. Vienna: Federal Ministry of Health; 2013 [cited 2013 Nov 21]. Available from: http://www.bmg.gv.at/cms/home/attachments/3/3/6/CH1100/ CMS1327680589121/impfplan2013.pdf. (In German.)
23. Ministry of Health and Social Welfare. Adult vaccination program [Internet]. Athens: Ministry of Health and Social Welfare; 2011 [cited 2013 Nov

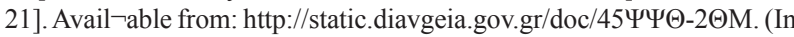
Greek.)

24. Regulation for the ammendment and extension to Regulation No 15 from 2005 on immunizations in the Republic of Bulgaria. Drzhaven Vestnik [Internet]. 2012 Oct 9 [cited 2013 Nov 21]:77. Available from: http://dv.parliament.bg/DVWeb/showMaterialDV.jsp?idMat=68970. (In Bulgarian.)

25. Vaktsiin.ee. Adult vaccination calendar, Estonia [Internet]. Tallinn: Vaktsiin.ee; 2013 [cited 2013 Nov 21]. Available from: http://www.vaktsiin. ee/arstile/taiskasvanute-vaktsineerimiskalender/. (In Estonian.)

26. Hungarian National Centre for Epidemiology. Vaccination guidelines 2012. Epinfo. 2012;19 Suppl 1:1-56. (In Hungarian.)

27. Baltic Immunoprophylactic Association. Lithuanian vaccination recommendations 2012 [Internet]. Vilnius: BALTIPA; 2012 [cited 2013 Nov 21]. Available from: http://www.baltipa.lt/data/Skiepai_A5_24ps1_ SPAUDAI 2.pdf. (In Lithuanian)

28. National Medicines Institute. Recommendations on the management of bacterial infections of the central nervous system [Internet]. Warsaw: National Medicines Institute; 2011 [cited 2013 Nov 21]. Available from: http://www.koroun.edu.pl/pdf/rekomendacje-ukl-nerwowy 2011.pdf. (In Polish.)

29. High Council of Public Health (HCSP). Opinion on the recommendations of vaccination for adults and children over 2 years at risk of invasive pneumococcal infection [Internet]. Paris: HCSP; 2013 [cited 2013 Nov 21]. Available from: http://www.hcsp.fr/Explore.cgi/Telecharger?NomFic hier=hcspa20130425_infectionsinvasivespneumocoque.pdf. (In French.)

30. National Institute for Public Health and the Environment (RIVM). Guideline for prevention of infec $\neg$ tions in (functional) hypo- and asplenia [Internet]. Bilthoven: National Institute for Public Health and the Environment (RIVM); 2012 [cited 2013 Nov 21]. Available from: http:// www.rivm.nl/dsresource?objectid=rivmp:52820\&type= $=$ org\&disposition $=$ inline\&ns $\mathrm{nc}=1$. (In Dutch.)

31. Government of Galicia, Ministry of Health. Instruction 012/2012: On the use of anti-pneumococcal thirteen-valent conjugate vaccine in persons 50 or more years of age belonging to risk groups [Internet]. Santiago de Compostela: Government of Galicia, Ministry of Health; 2012 [cited 2013 Nov 21]. Available from: http://www.sergas.es/gal/DocumentacionTecnica/ docs/SaudePublica/vacunas/PNEUMO conxugada adultos firmada. pdf. (In Galician.)

32. Federal Ministry of Health (BAG); Federal Commission on Vaccination (EKIF). Recommendations for the vaccination of recipients of blood stem cells. Bull Bundesamt Gesundh [Internet]. 2012 [cited 2013 Nov 21];(21):363-70. Available from: http:/www.bag.admin.ch/themen/ medizin/00682/00684/02535/. (In German.)

33. UK Department of Health. Pneumococcal the green book, chapter 25 [Internet]. London: UK Department of Health; 2013 [cited 2013 Nov 21]. Available from: http://immunisation.dh.gov.uk/green-book-chapters/chapter-25/.

34. Recommendations of the Standing Committee on Vaccination (STIKO) at the Robert Koch Institute. Update July 2012: Vaccination calendar. Epidemiologisches Bull. 2012;(30):284-5. (In German.)

35. Skoczyńska A, Sadowy E, Bojarska K, Strzelecki J, Kuch A, Gołębiewska A, et al.; Participants of laboratory-based surveillance of community acquired invasive bacterial infections (BINet). The current status of invasive pneumococcal disease in Poland. Vaccine. 2011 Mar 3;29(11):2199-205.

Received September 17, 2013 Accepted in November 3, 2013 